\title{
Monitoring the mode of action of synthetic and natural biocides against Aeromonas hydrophila by Raman spectroscopy and chemometrics
}

\author{
Megha Mehta ${ }^{1 *}$, Yang Liu', Mark Waterland ${ }^{2}$ and Geoff Holmes ${ }^{1}$
}

\begin{abstract}
We have investigated the mode of action of synthetic biocides, (2-(thiocyanomethylthio) benzothiazole(TCMTB), dichlorophen, (commonly used in leather industry for preservation) and natural biocides, oregano and eucalyptus oils, on Aeromonas hydrophila using Raman spectroscopy in collaboration with multivariate analysis and 2D correlation spectroscopy to evaluate whether Raman spectra acquired contained valuable information to study the action of biocides on bacterial cells. The growth of A. hydrophila in clear and outer edge zone of inhibition differ in their reaction with different biocides, which allows us to highlight the differences as a characteristic of two kinds of bacteria. Such classification helps identify oregano oil as the most effective biocide by altering clear and outer edge zone of bacteria. Standard disk diffusion assay method was used for screening biocide bacteria interactions and later analysed by Raman spectroscopy. The paper also presents the introduction of TCMTB and oregano oil into leather processing stages to examine and determine the antimicrobial effect as an application to real-world setting. Therefore, we conclude that Raman spectroscopy with appropriate computational tools constitutes a powerful approach for screening biocides, which provide solutions to all the industries using biocides including leather industry, considering the potentially harmful effect of biocides to humans and the environment.
\end{abstract}

Keywords: Biocides, Chemometrics, Aeromonas hydrophila, Principal component analysis, Raman spectroscopy, Inhibition

\section{Introduction}

Microorganisms are present everywhere in different proportions, sizes, and diverse habitats. Microorganisms can be useful, harmful, dangerous, or degrade materials. In the leather industry, raw hides or skins and intermediates or even final leathers are always under microbial attack, resulting in downgrading or even complete destruction by microbes. So-called "weapons" to fight against harmful micro-organisms are biocides intended to kill living microorganisms responsible for decomposition and destruction of valuable materials, disturb the

\footnotetext{
* Correspondence: megha.mehta@lasra.co.nz

${ }^{1}$ NZ Leather and Shoe Research Association (LASRA $\left.{ }^{\oplus}\right)$, Palmerston North, New Zealand

Full list of author information is available at the end of the article
}

production processes and influence the quality of final products [1]. But chemical biocides potentially pose a risk to the environment and human health if not handled, or processed, correctly. The prevention of microbial growth and multiplication in leather materials entails the use of biocides i.e., bactericidal, or biostatic chemicals. If any contamination due to bacteria or mould happens during leather processing, the damage cannot be reversed which can affect the quality of leather and poses a significant economic loss for the tanneries [2]. Accordingly, in principle, tanneries have a great interest in protecting their leather intermediates from microorganisms by a chemical treatment. The key questions that arise in selecting these biocides include which chemicals can be and should be used and what 
are the advantages of the biocide's chemical origin? Will it be safe in use for humans and the environment?

The unavoidable use of chemicals in the leather industry and its production processes represents an environmental impact. As stated before, biocides are a must for the leather industry as there are no feasible alternatives that guarantee long-term protection of partially processed material, held in a wet state for many months during transport and storage. The globalization of the leather market and the resulting international trade of these materials in the wet state make it necessary to protect the goods using biocides [3]. Therefore, any industry using biocides should commit to protecting consumers, workers, and the environment. "Restricted Substances Lists" (or more commonly referred to as RSLs) can be found in the REACH regulations [4], i.e., Regulation of the European Parliament and of the Council concerning the Registration, Evaluation, Authorisation, and Restriction of Chemicals to direct suppliers in the production of safe and compliant products. Some biocides, like pentachlorophenol (PCP), are hazardous for human health and life and have been withdrawn from use [5].

In consideration of synthetic biocides' harmful effects, an investigation was undertaken to replace these agents with natural and environmentally friendly substances of plant origin, i.e., essential oils with antimicrobial properties. Nature has also developed so-called "natural biocides", derived from e.g. plants or even bacteria [6]. A few of the common synthetic biocides used in the leather industry are 4-chloro-3- methylphenol (PCMC), 2-phenylphenol (OPP), and 2-(thiocyanomethylthio) benzothiazole (TCMTB) $[1,3]$. Some studies have shown proven antimicrobial activity of natural biocides, including essential oils [3, 7-9], indicating that it is possible to eliminate the harmful effect of synthetic bioactive agents on humans. This also indicated a possibility for improving the leather-making process with a view of ecological aspects. Essential oils have attracted the interest of scientists [10-12] for several years. Bacterial resistance to biocides has also become a great concern.

To investigate the possibility of finding the best and long-lasting antimicrobial action, firstly, we have selected commonly used synthetic biocides including 2-(thiocyanomethylthio) benzothiazole (TCMTB), dichlorophen (DCP), as well as oregano and eucalyptus oils from the organic class of essential oils. Secondly, there is a need to identify a potential identification technique. There are several conventional methods being used in microbiology include the broth micro and microdilution test, agar diffusion test and automated susceptibility testing systems [13]. The disk diffusion method is the gold standard for confirming the susceptibility of bacteria and was introduced by Bauer and Kirby's experiments in 1956, after finalizing all aspects of optimization by changing physical conditions [14]. Such methods are often time-consuming, expensive and may offer only limited information. Considering all these limitations, it is important that novel technologies be developed that can rapidly detect and predict the emergence of antimicrobial resistance. Raman spectroscopy has the potential to fingerprint bacteria and study antimicrobial resistance since even minute biochemical changes can be rapidly detected [15]. The extent of cellular damage and the resulting Raman spectral changes are often a function of the biocide concentration. Therefore, it is important to understand the impact of biocide concentrations on the biomolecular profile of bacteria. The bacterium Aeromonas hydrophila was tested for its resistance to these biocides of different concentrations using Raman spectroscopy. A. hydrophila, a Gram-negative, oxidasepositive, motile, non-spore-forming, facultative anaerobic bacterium was selected for the study which is usually considered an opportunistic aquatic pathogen with resistance to commercial antibiotics [16]. This strain was recommended for the tests because of its general activity on untreated skins and compost [17]. We have obtained a whole-microorganism fingerprint for this bacterium using Raman spectroscopy with an excitation wavelength of 532 $\mathrm{nm}$, which has already been proven very successful in rapidly discriminating and identifying microorganisms [18]. The vibrational spectrum inherently serves as a fingerprint of the biochemical composition of each bacterium and thus makes identification at the species level, or even the subspecies level, possible. For better visualisation and separation of classes within each Raman spectral dataset, multivariate analysis and two-dimensional correlation spectroscopy (2D-COS) was employed to highlight the variance.

The next step in the current work is applying knowledge and experience obtained from the bacteria biocide susceptibility results for testing real leather samples by introducing these biocides at different stages of leather processing to evaluate the effectiveness in protecting the leather from damage caused by microorganisms. The study demonstrates a comparison of the mode of action of natural biocides with those of commercially available synthetic biocides used in tanning.

\section{Materials and methods}

\subsection{Biocides and bacteria}

$A$. hydrophila was used as a model microorganism isolated from sheep skin. The identified strain of $A$. hydrophila was cultured for $24 \mathrm{~h}$ at $37^{\circ} \mathrm{C}$ and stored for downstream application as stock cultures at $-80{ }^{\circ} \mathrm{C}$ in Luria Broth (LB) medium with 30\% glycerol [19]. 30\% 2(thiocyanomethylthio)benzothiazole (TCMTB; trade name Busan 30) was obtained from Buckman laboratories, USA, 30\% dichlorophen was obtained from Prime Trading Company, New Zealand, eucalyptus oil (80-85\% 
cineole) obtained from Lotus Essential Oils and 100\% pure Oregano oil was obtained from Amazing Herbs with $90 \%$ carvacrol content. All these biocides were diluted in 10\% dimethyl sulfoxide (DMSO; SigmaAldrich Co., USA) to get the desired concentration. 10\% DMSO was used as a control to monitor the effect of biocide on bacterium species.

The antimicrobial activity of selected synthetic biocides - TCMTB and dichlorophen and essential oilsoregano and eucalyptus oil were determined following the Kirby-Bauer Disk Diffusion Susceptibility Test Protocol [14]. Three different biocide concentrations of $0.3 \%$, $3 \%$, and $30 \%$ in $10 \%$ DMSO diluted in milli-q water were prepared to monitor the effectiveness against $A$. hydrophila bacterial strain. Before testing, the bacterial strain was streaked on LB Agar and incubated for $24 \mathrm{~h}$ at $37^{\circ} \mathrm{C}$. Isolated colonies were touched using an inoculating loop and suspended in $2 \mathrm{~mL}$ of phosphate buffer solution (PBS). After vortex mixing, the turbidity of the bacterial suspension was adjusted to match $0.5 \mathrm{McFar}-$ land standard. Mueller Hinton agar plates were inoculated by streaking the swab dipped into the inoculum suspension over the entire agar surface. A volume of $10 \mu \mathrm{L}$ of each biocide was added to Oxoid ${ }^{\mathrm{m}}$ Blank Antimicrobial Susceptibility Disks (CT0998B, Thermo Fisher Scientific) and transferred to the inoculated MuellerHinton agar plates incubated for $18 \mathrm{~h}$ at $37^{\circ} \mathrm{C}$. The antibacterial activity was evaluated after incubation time by measuring the inhibition zone using a ruler. The disk diffusion assay was performed in duplicate, and the mean and standard deviation value of inhibition zone was calculated (Table 1).

For Raman spectroscopic measurements, the bacterial colonies formed on agar plates were smeared by picking the biomass from the clearing zone (the innermost zone),' and the edge ring of the clear zone separately using an inoculation loop onto the $\mathrm{CaF}_{2}$ substrate (polished, Raman grade, Crystran Ltd., United Kingdom) [20]. This allowed us to create a distinction between clear and outer edge zone of $A$. hydrophila against the action of the biocides. Raman spectra were collected immediately after sample preparation to avoid sample

Table 1 Disk diffusion determined zones of inhibition ( $\mathrm{mm}$ ) for A. hydrophila strain after treatment with TCMTB, DCP, oregano oil and eucalyptus oil

\begin{tabular}{|c|c|c|c|c|c|c|}
\hline \multicolumn{7}{|c|}{ Mean value $(\mathrm{mm}) \pm$ Standard Deviation } \\
\hline \multirow[t]{2}{*}{ Biocides } & \multicolumn{2}{|l|}{$0.30 \%$} & \multicolumn{2}{|l|}{$3 \%$} & \multicolumn{2}{|l|}{$30 \%$} \\
\hline & Mean & S.D. & Mean & S.D. & Mean & S.D. \\
\hline TCMTB & 17.23 & \pm 0.23 & 26 & \pm 0.15 & 40 & \pm 0.29 \\
\hline DCP & 11.14 & \pm 0.5 & 18 & \pm 0.61 & 28 & \pm 0.48 \\
\hline Oregano oil & 9.27 & \pm 0.05 & 20 & \pm 0.13 & 41 & \pm 0.09 \\
\hline Eucalyptus oil & 0 & & 0 & & 10 & \pm 1.2 \\
\hline
\end{tabular}

degradation in the dehydrated state. To obtain the normal Raman spectrum of selected biocides and A. hydrophila, $5 \mu \mathrm{L}$ of biocide or bacterial culture was air- dried on the $\mathrm{CaF}_{2}$ substrate for $30 \mathrm{~min}$.

\subsection{Biocides, bacteria and leather treatment}

Individual treatments on raw cowhide pieces were carried out by introducing TCMTB ( $1 \%$ of leather weight) and oregano oil ( $2 \%$ and $3 \%$ of leather weight) during the leather processing. The standard leather processing protocol with the addition of TCMTB and oregano oil is followed and presented in Fig. S1. Antimicrobial activity was evaluated after 1 week of leather finishing. The control samples were also prepared without the action of any biocide during the process. After 1 week, for microbiological testing, round-shaped disks of diameter 12 $\mathrm{mm}$ were collected from finished leathers by means of a punching tool. Rest leather samples were stored in paper bags to retain the moisture for further testing in the future. Control samples were also preserved under similar conditions.

\subsection{Data acquisition and Raman spectral processing}

The samples were analysed using a custom-built Raman microscope based on an inverted IX71 Olympus microscope A. $532 \mathrm{~nm}$ excitation laser (with $10 \mathrm{~mW}$ laser power) was focused onto the sample with a spot size diameter of $1-2 \mu \mathrm{m}$ using $40 \times$ magnification and 0.65 NA objective. A Raman edge filter ( $12^{\circ}$ incident angle) (Iridian Spectral Technologies, Ontario, Canada) directed the excitation into the sample and rejected the Rayleigh scattered light. An additional Raman edge filter (normal incidence) was used to remove any residual Rayleigh scattering immediately before entering the spectrometer. The Raman scattered light was focussed onto a 50- $\mu \mathrm{m}$ entrance slit of a Teledyne-Princeton Instruments FERGIE spectrometer. Bacterial samples collected from clear and outer edge zone were dried onto $\mathrm{CaF}_{2}$ substrate. Five samples of each biocide concentration were prepared, and Raman spectra were acquired with an exposure time of $5 \mathrm{~s}$ per frame over 10 frames (each frame was saved separately). From each dried sample, at least 30 spectra were collected from different regions of the sample. The collected spectra were pre-processed with an algorithm written using the SciKit Learn package [21] in Python 3.7. Baseline correction, background subtraction, and average spectra were obtained using the Python algorithm. The spectral data was smoothed using the five-point Savitzky-Golay smoothing function to smooth out spectral noise, and normalization was done by dividing each point by the norm of the whole spectrum using Origin 2021b. For visualization, spectra were scaled between 0 and 1 and offset in increments of 1 . 
To investigate the relationship between Raman spectroscopy and the biocide effect on A. hydrophila, multivariate statistical method, Principal Component Analysis (PCA) was used to reduce the dimensionality of the Raman data whilst preserving the large variance. Principal Component Analysis was performed using Origin 2021 b. Multivariate statistical methods are popular methods for spectral analysis for biological specimens, but these methods cannot reveal the dynamic spectral alterations due to external perturbations of biological systems. To address this respect, two-dimensional correlation spectroscopy, a cross-correlation method, was used to monitor dynamic fluctuations of spectral signals [22] and identify which signal contributes the most. 2D correlation spectra were constructed to study bacterial changes reflected in Raman spectra with increasing biocide concentration. An average of five replicates of each concentration of biocide was used to demonstrate one-dimensional spectra for 2D correlation analysis.

There were two sets to demonstrate 2D correlation spectra - synchronous spectra characterised by auto peaks along the diagonal and cross peaks off the diagonal shows some similarities in the dynamic behaviour. If there is no change in spectra, it will not appear in $2 \mathrm{D}$ spectra.

\section{Results and discussion}

\subsection{Disk diffusion agar plate test}

Round disks of $6 \mathrm{~mm}$ diameter were analysed for the determination of bacterial susceptibility to four selected biocides. Bacteria suspensions were streaked over the plate. The disks with selected biocides were placed in the centre of agar plates. After leaving it for a day to allow biocide to induce bacteria-biocide interactions, there is an appearance of two zones formed by bacteria; one shows a clear zone with bacterial inhibition and another outer edge zone with bacteria resistant to inhibition (Fig. 1). The bacterial biomass from the clear and edge zones was collected and analysed using Raman spectroscopy. The clear zone in the plate indicates that bacteria have been killed by biocide and the outer edge zone indicates biocide diffusion into the zone area and inhibition of bacterial growth [23]. Clear and edge zones of $A$. hydrophila differ in their response to different biocides, highlighting the differences as a characteristic of two kinds of $A$. hydrophila bacterium.

Using the disk diffusion assay as a screening method, all selected biocides showed measurable inhibition zones. The antibacterial activity for A. hydrophila after treatment with TCMTB, dichlorophen, oregano oil and eucalyptus oil is determined by the means and standard deviation of zones of inhibition in millimetres as shown in Table 1.

The results reveal that TCMTB showed a higher inhibition zone than dichlorophen, whereas oregano oil showed the highest inhibition level than eucalyptus and proved the most effective among all at 30\% concentration.

\subsection{Raman spectroscopy identifies biomolecular changes due to biocide treatment}

To examine the mechanism of action of these biocides and to support the results from the disk diffusion assay

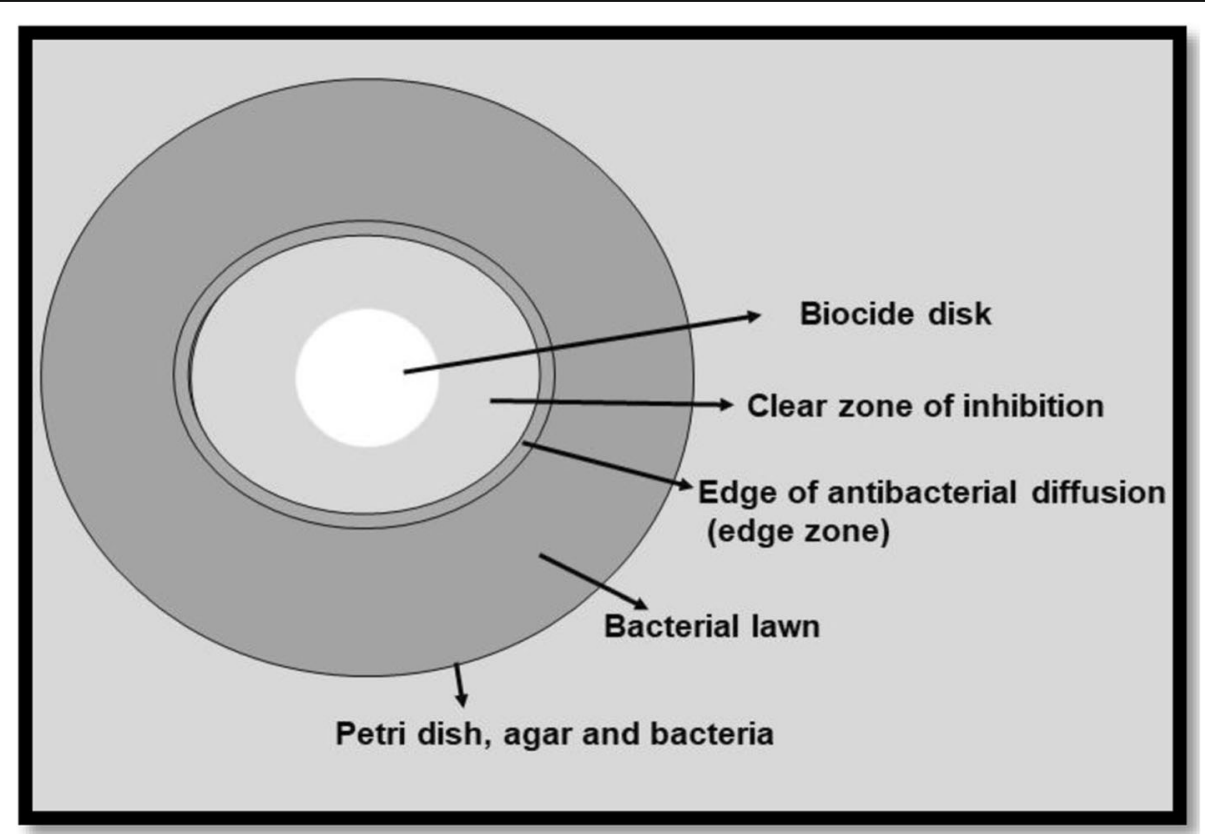

Fig. 1 Zones on biocide assay plates 
method, Raman measurements were performed on samples obtained from clear and outer edge zone of $A$. hydrophila after biocide treatment. Raman bands as shown in Fig. 2 at 746, 1125, 1304, and $1581 \mathrm{~cm}^{-1}$ are characteristic of the vibrational modes of cytochrome proteins [24-26]. Cytochrome c belongs to class I of the c-type cytochrome family and has a $\mathrm{CXXCH}$ (cysteineany-any-cysteine-histidine) amino acid pattern that binds heme [27]. The in-plane $\Pi \rightarrow \Pi^{*}$ transitions of the porphyrin ring are responsible for strong resonant Raman scattering [28]. Cytochrome c, a growth/decay marker within $A$. hydrophila, was monitored to detect the biochemical changes by means of Raman spectroscopy. Peaks at 881 , and $976 \mathrm{~cm}^{-1}$ are assigned to the $v(\mathrm{C}-\mathrm{C})$ stretch of lipids and $\mathrm{C}-\mathrm{C}$ stretch, $\alpha$-helix of proteins, and the peak at $1163 \mathrm{~cm}^{-1}$ is characteristic of phenylalanine. The peak at $1444 \mathrm{~cm}^{-1}$ is usually due to the $\mathrm{CH}_{2}$ deformation (wagging) of protein [29]. The Raman band centred at $1645 \mathrm{~cm}^{-1}$ represents the amide I of collagen protein, which typically consists of several secondary structures [30]. The detailed assignments were tabulated in Table S1.

Figure $3 \mathrm{a}, \mathrm{b}, \mathrm{c}$, and d show the Raman spectra of $A$. hydrophila cells grown in the presence and absence of selected biocides. 10\% DMSO control without any biocide was carried out for monitoring the mode of action of bacteria. Pure DMSO has strong antibacterial effect but we have diluted biocides in $10 \%$ dimethyl sulfoxide to get the desired concentration [31]. No antimicrobial activity was detected by DMSO. 10\% DMSO control was carried out with each test to ensure that microbial growth was not inhibited by DMSO itself. The samples

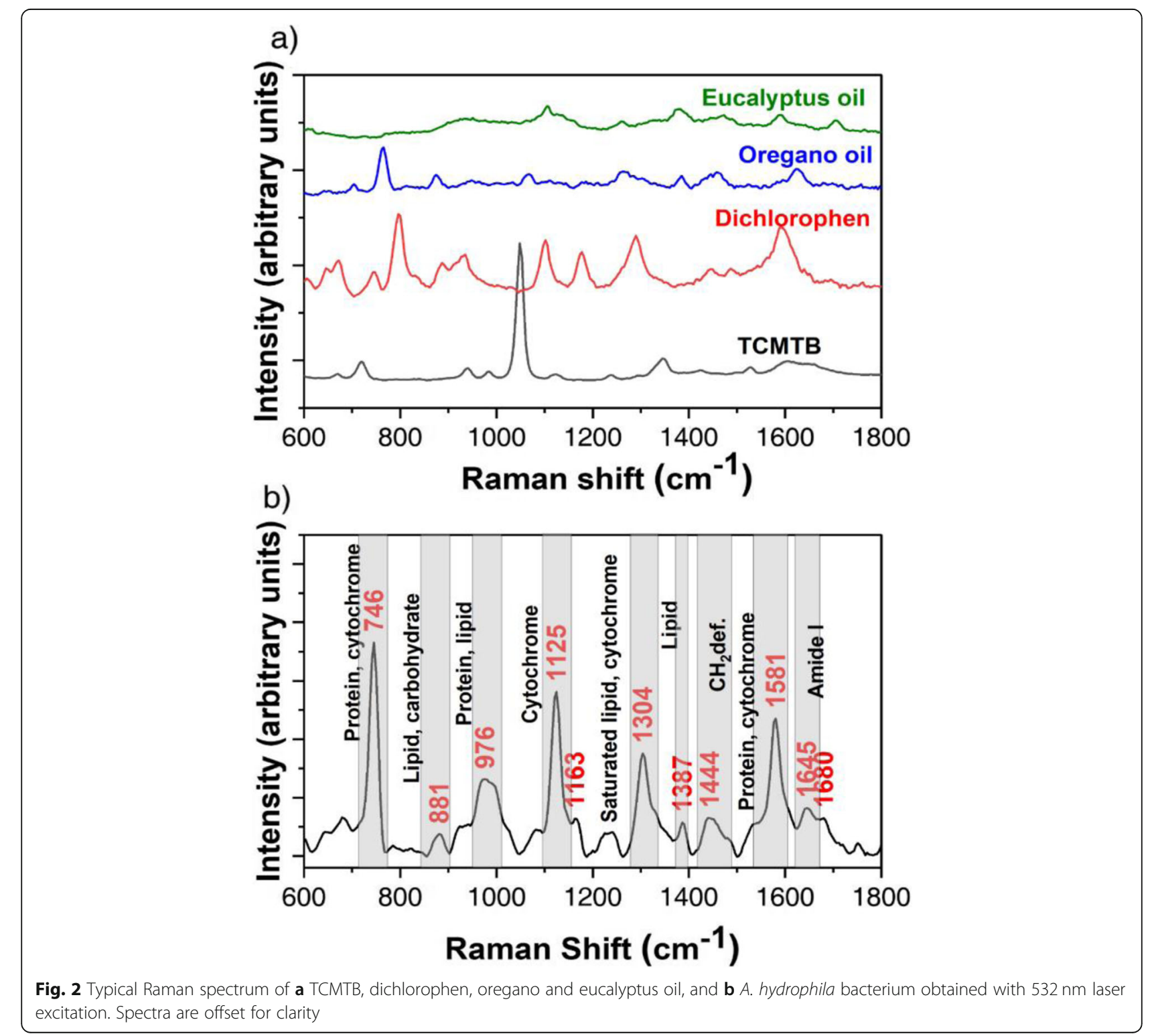




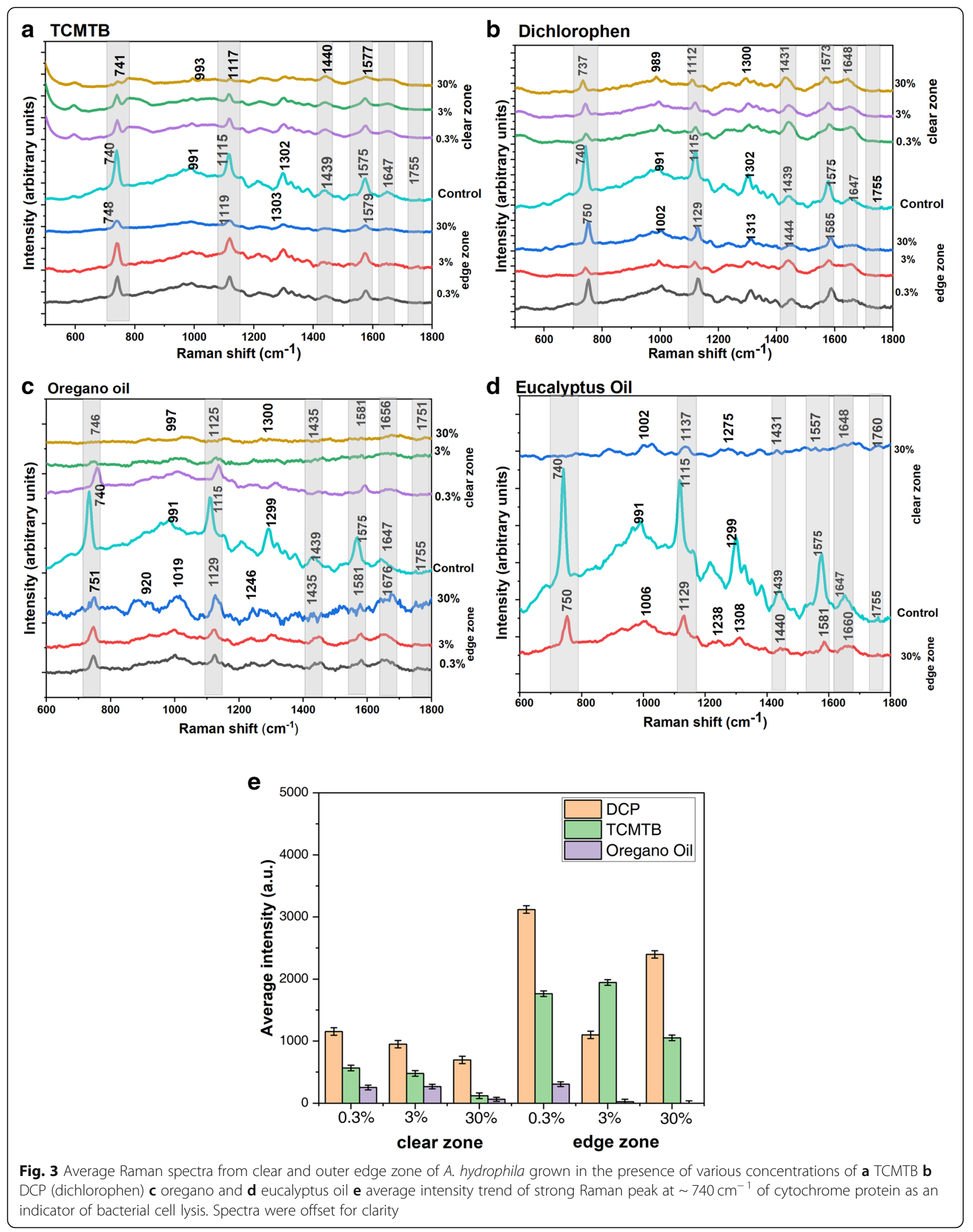


were obtained from clear and outer edge zone after biocide treatment for Raman analysis. The spectra in Fig. 3 appear to be qualitatively similar to the typical Raman spectrum of $A$. hydrophila bacterium, but on closer inspection, some quantitative differences can be found, particularly changes in the cytochrome marker peaks with slight shifts in peak position. Raman spectra of cytochrome proteins was obtained using a $532 \mathrm{~nm}$ laser line which shows strong resonance enhancement [32, 33] with characteristic bands located in the spectral range of $740-760 \mathrm{~cm}^{-1}$ that originates from pyrrole breathing [34]. The excitation at $785 \mathrm{~nm}$ is far from resonances of cytochromes therefore $532 \mathrm{~nm}$ was chosen as a preferred excitation wavelength [35].

Among synthetic biocides, TCMTB demonstrates significant decrease in the intensity of marker bands (suggesting evidence of alterations cell wall structure) with increase in biocide concentration. The spectra classify into two classes - the clear zone representing the signature of dead bacteria and outer edge zone of live bacteria. Dichlorophen shows an intense Raman signal in both zones at all concentrations, which explains it is less effective in bacteria inhibition. In another set of essential oils, oregano oil works the best compared to eucalyptus oil, which was ineffective at low concentrations and works effectively at $30 \%$ concentration. The mechanism of action of biocides is diverse and bacterial susceptibility of biocides is target site-specific. It is easier for a few biocides to find the target site that impacts biocide attraction to bacterial cells and leads to structural alterations in bacterial cells, allowing the bacteria to expel the cell [36]. Raman spectral results are consistent with the inhibition zones measurements from the disk diffusion method. The decreased peak at $746 \mathrm{~cm}^{-1}$ served as a good indicator for cell lysis after biocide treatment. It was previously studied that the decrease of cytochrome Raman intensity bands was related to the conformational changes of proteins, which correlated with the cell death [37]. To quantitatively identify the effect of biocides on the variation in A. hydrophila bacterium, we have investigated the Raman peak at $\sim 746$ $\mathrm{cm}^{-1}$, and its average peak intensity were calculated (Fig. 3e). The outer edge zone has higher bacterial content compared to the clear zone, which differentiates both live and dead bacteria. Figure 3a for TCMTB, for the clear zone, the band at $741 \mathrm{~cm}^{-1}$ for $30 \%$ TCMTB is much weaker than those of $0.3 \%$ and $3 \%$. In Fig. 3d., the band at $750 \mathrm{~cm}^{-1}$ for the edge zone is observed at minimum for $3 \%$ as compared to both $0.3 \%$ and $30 \%$ whereas clear zone concentrations have similar intensity which indicates different concentrations have minimal effect on microbial resistance. In Fig. 3c, for oregano oil clear zone shows that, at $0.3 \%$ the band at $740 \mathrm{~cm}^{-1}$ is quite visible, while at $3 \%$ it can be hardly be distinguished from noise, very low in intensity and it is completely absent at $30 \%$. It demonstrates that oregano oil has the least bacterial cells that indicate cell death in clear and edge zones of bacteria.

The effect of biocides is reflected by changes in the spectra affecting most protein peaks. Oregano oil alters the biochemical components of clear zone as well as outer edge zone. Generally, the cell wall structure is the target of biocides and these cytochrome bands are good indicators for sensitive detection of cell wall modification. As the $746 \mathrm{~cm}^{-1}$ band decreases due to biocide treatment, we can conclude that cell wall structure is modified, and the bacteria undergo lysis with a substantial reduction in survival rate. Therefore, oregano oil is a suitable choice as a biocide with no risk to the environment and human health.

From the results obtained, we have demonstrated that the Raman method developed could sense the biochemical changes of $A$. hydrophila after different biocide treatments in the early stage, which helps to discriminate the treatments and clearly show that, Raman spectra of control bacterial cells, bacterial cells treated with TCMTB, dichlorophen, oregano oil, and eucalyptus oil were compared. These differences were directly related to the different modes of actions of these biocides and the cell wall integrity under the different treatments.

\subsection{Multivariate analysis}

Although we have observed the spectral variations in bacterial cells after treatment with biocides, but to confirm this hypothesis and for better representation of variations in differentiating the clear and outer edge zone bacteria, multivariate analysis that is Principal Component Analysis (PCA) was employed. PCA was applied on average baselined spectral data obtained from five replicates of A. hydrophila bacterium - TCMTB and oregano oil samples. PCA analysis will help to identify the variations and quickly characterise the "types" or "classes" of spectra or samples present in a large data set [38]. Figures 4 and 5 illustrate the two-dimensional representation of PCA results of TCMTB and oregano oil treatment on $A$. hydrophila. PCA plot of the dataset demonstrates the separation of samples of control, clear and outer edge zone bacteria in the form of clusters. The average control (without any biocide) spectrum was used to highlight the difference. PC1 explains $71.1 \%$ of the variance projecting the highest variation in the data, differentiating the spectral features of clear zone, outer edge zone and control. Outer edge zone bacteria and control are quite well separated by $\mathrm{PC} 2$ that explains $25.7 \%$ of the variance. Control and outer edge bacterial zone spectral data closely match and clustered together. The control spectra overlap with the outer edge zone of 

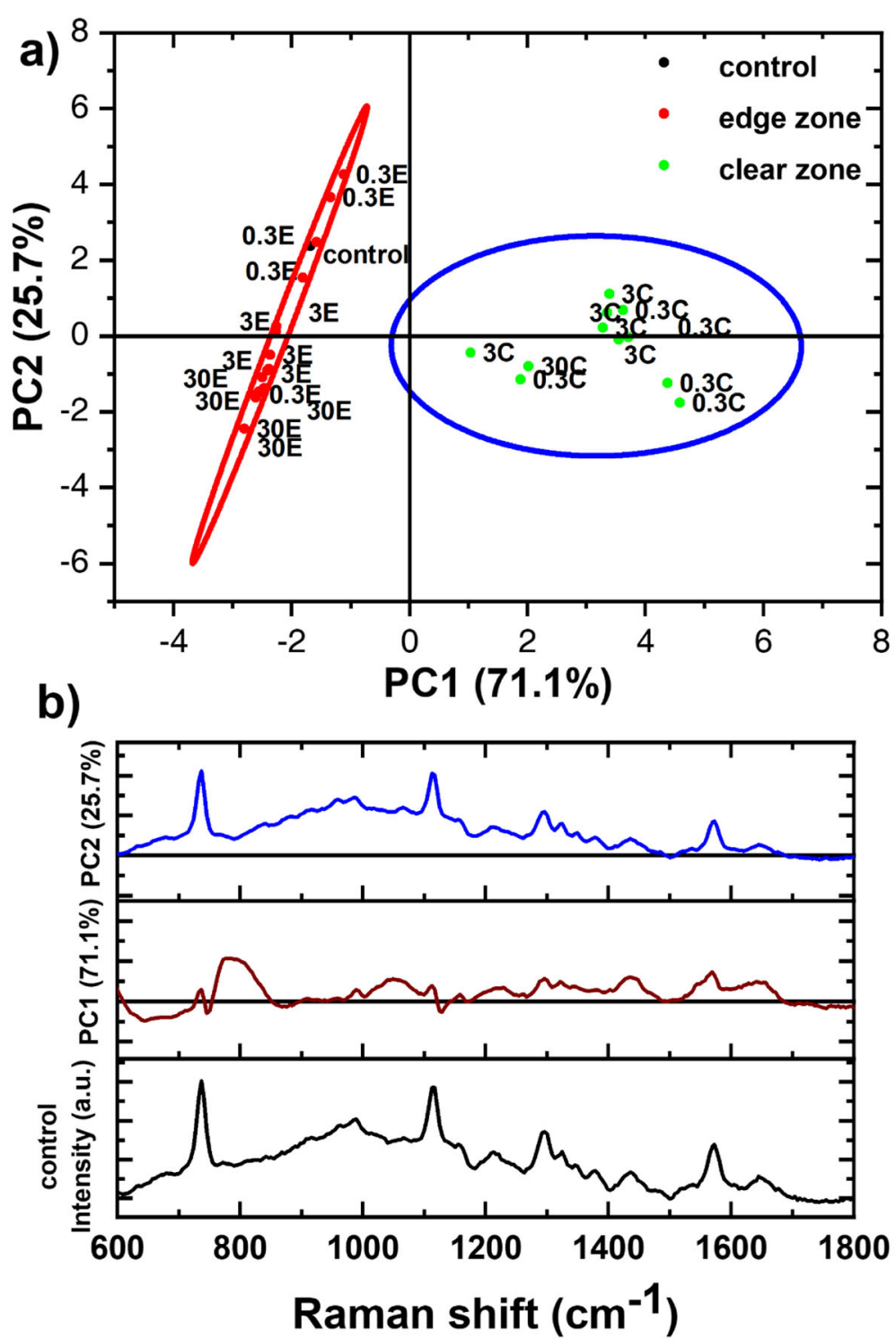

Fig. 4 PCA a score plot and $\mathbf{b}$ loading plot of TCMTB affected A. hydrophila. Raman data plotted for PC1 and PC2 with increasing concentrations $(0.3 \%, 3 \%$ and $30 \%)$. Spectra were offset for clarity

bacteria and are differentiated from the clear zone where cell lysis occurs. Figure 5a shows the PCA scores plot of bacteria affected by oregano oil, which do not show any separation between clear and outer edge zone bacteria, but there is an overlap of spectra within concentrations. This supports the hypothesis that oregano oil has not only killed the bacteria within the clear zone but also affected the bacteria through diffusion to outer edge zone.

To analyse the spectral variations in the Raman data described by the principal component, loading plots of TCMTB and oregano oil were displayed in Figs. $4 \mathrm{~b}, 5 \mathrm{~b}$. The Raman peak at $\sim 740 \mathrm{~cm}^{-1}$ and $\sim 1125 \mathrm{~cm}^{-1}$ feature prominently in the loadings, which is negatively correlated to the biocide concentration in Fig. 4b PC1 plot.
This inverse behaviour means there is an increase in deformation of cell wall with increasing TCMTB concentration. There are peaks at $\sim 1300$ and $1575 \mathrm{~cm}^{-1}$ which are positively correlated and attributed to lipids and cytochrome protein content. The loadings plot of oregano oil (Fig. 5b) demonstrates that PC1 has all positive correlated bands attributed to cytochrome whereas PC2 shows inverse behaviour from several alterations happening with increase in oregano oil concentration.

\subsection{Two-dimensional correlation spectroscopy (2D-COS)}

To further explore the potential of Raman spectroscopy in identifying the mode of action of biocides, 2D correlation spectroscopy was employed. It was assumed there 


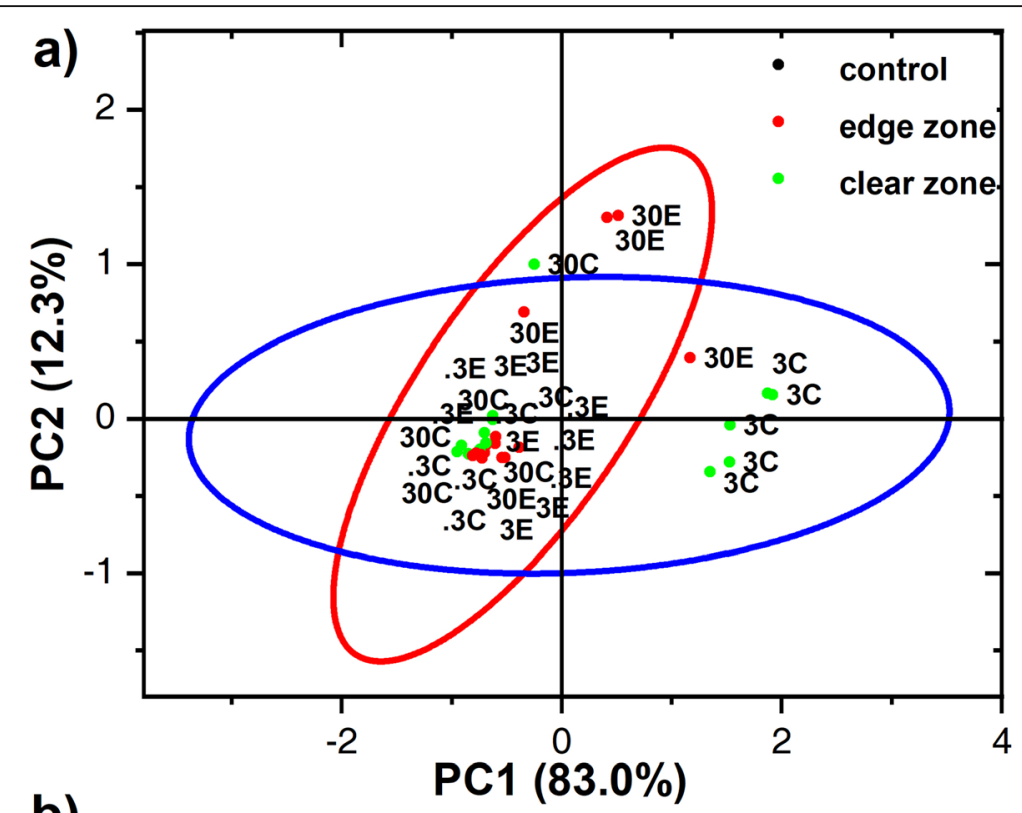

b)

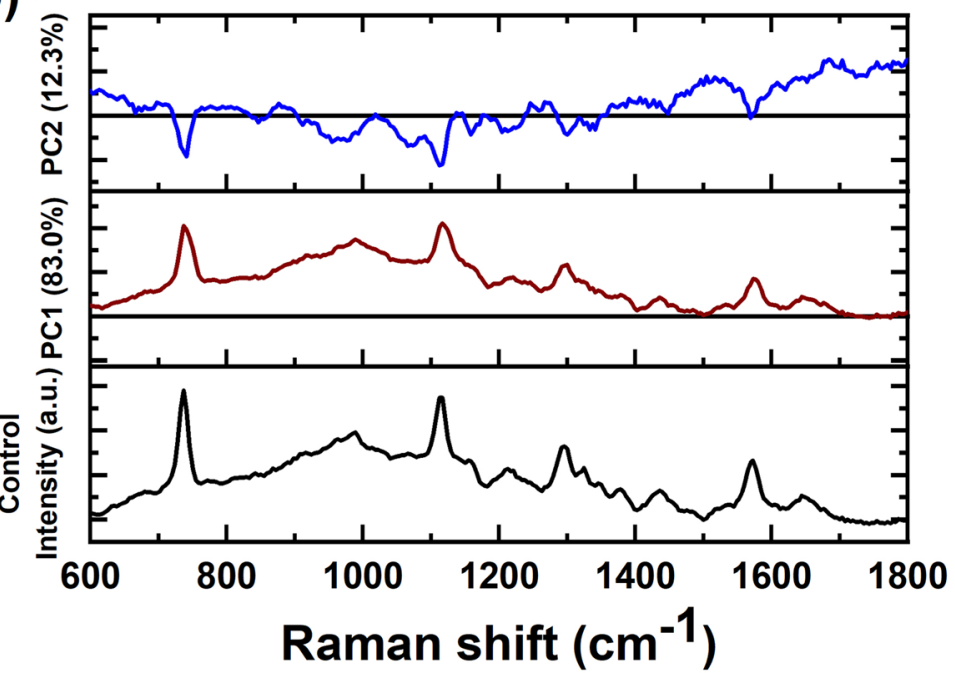

Fig. 5 PCA a score plot and $\mathbf{b}$ loading plot of oregano oil affected A. hydrophila. Raman data plotted for PC1 and PC2 with increasing concentrations $(0.3 \%, 3 \%$ and $30 \%)$. Spectra were offset for clarity

is a shift in the cytochrome protein band at $746 \mathrm{~cm}^{-1}$ which is due to symmetric vibrations of pyrrole rings [28] whereas the 2D correlation spectra shows major variations in bacterial vibrational modes after TCMTB and oregano oil treatment within the range of $730 \mathrm{~cm}^{-1}$ to $740 \mathrm{~cm}^{-1}$ that overlaps with DNA nucleobase assignment. It is assumed that this may be related to protein-induced distortions and conformational changes after interaction with different biocides using $532 \mathrm{~nm}$ laser wavelength.

It was also found that band at $737 \mathrm{~cm}^{-1}$ can be assigned to pyrrole folding mode and/or symmetric vibrations of cytochrome proteins [28]. Although cytochromes are present in almost all kinds of living cells, due to their low concentration in the cell only the reduced form of cytochrome $\mathrm{c}$ in functional cells has a sufficiently strong enhancement to be noticed in Raman spectra. The oxidized form of cytochrome $c$ is characterized by less signal intensity and often overlapped by other bands [39].

Figures 6, and 7 show the full 2D COS plot of the spectra of TCMTB and oregano oil of clear and outer edge zone of $A$. hydrophila. The synchronous plot shows that there are correlations between almost all the bands in the spectra. But the asynchronous plot shows specific interactions between bacteria and biocides [40]. In the synchronous plot of TCMTB clear zone (Fig. 6a), three 

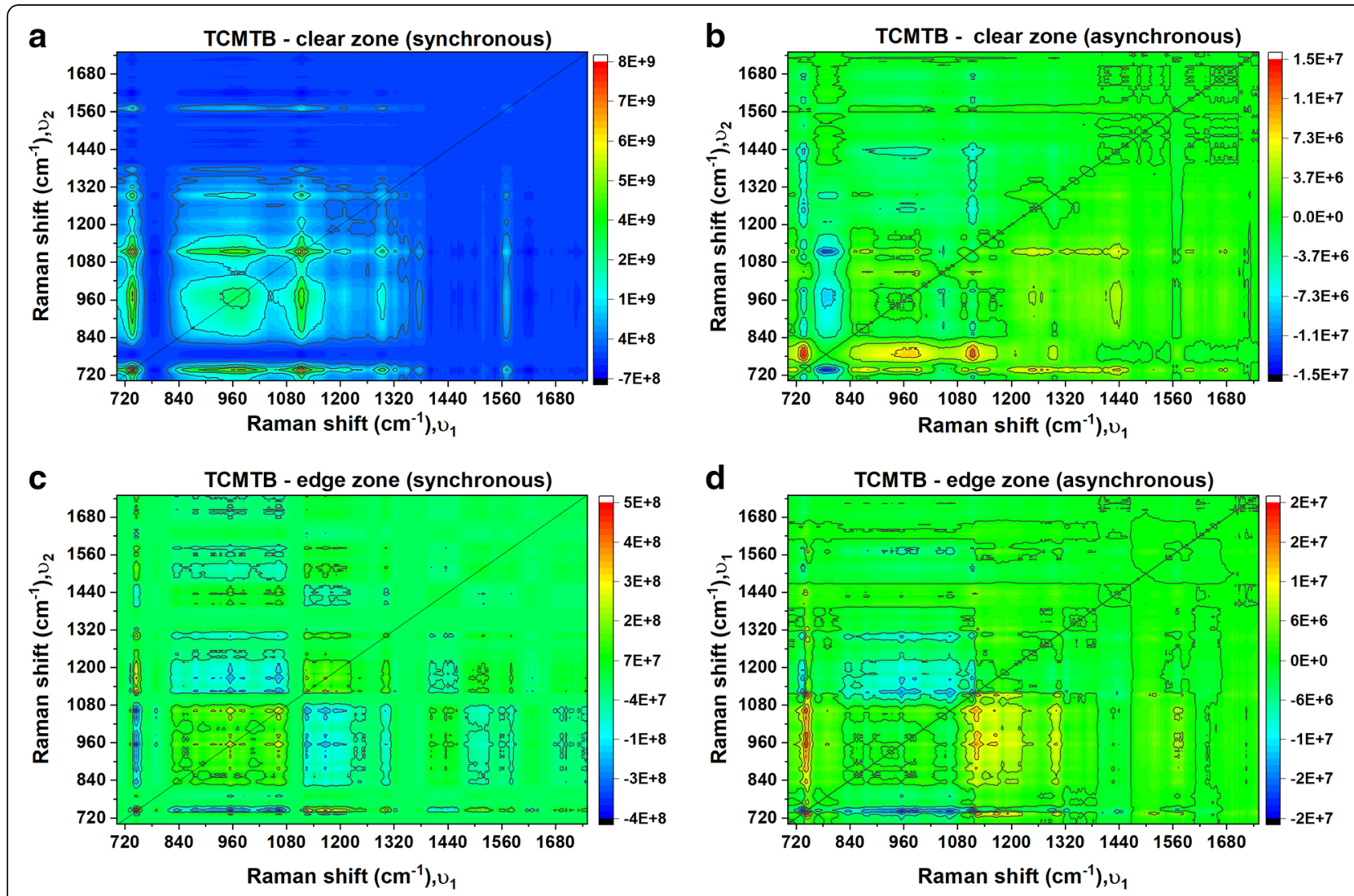

Fig. 6 Synchronous $(\mathbf{a}, \mathbf{c})$ and asynchronous $(\mathbf{b}, \mathbf{d})$ correlation spectra of clear and outer edge zone of bacterial cells exposed to TCMTB ranging concentrations from 0 to $30 \%$. (Intensity colour scale on the left)

autopeaks were observed at 737,976 , and $1125 \mathrm{~cm}^{-1}$ indicating the intensity of these bands change with increase in TCMTB concentration. The band at $737 \mathrm{~cm}^{-1}$ could be attributed to cytochrome proteins or DNA vibrational mode and thus be considered a measure of protein or nucleic acid content of bacteria cells. The band at $976 \mathrm{~cm}^{-1}$ attributed to $\mathrm{C}-\mathrm{C}$ stretch of proteins and lipids has only contributed to the clear zone synchronous map whereas the asynchronous map of clear zone (Fig. 6b) has spread over the wider wavelength range from 850 to $1050 \mathrm{~cm}^{-1}$. The band at $1125 \mathrm{~cm}^{-1}$ is attributed to cytochrome proteins and lipids related to bacterial decay with increase in concentration. The synchronous plot of outer edge zone with TCMTB (Fig. 6c), shows one autopeak at synchronous plot with highest intensity peak at $740 \mathrm{~cm}^{-1}$ that increase with concentration whereas asynchronous plot (Fig. 6d) shows the two cross-peaks as two lobes, one positive and one negative observed close to the diagonal, possibly demonstrating either a shift in band or correlated behaviours of overlapped bands.

To understand in detail the dynamics of important spectral peaks with increase in the concentration of biocide from 0 to $30 \%$, we take a look at individual bands in the range of $737-750 \mathrm{~cm}^{-1}$, an important band to find an evidence of the alterations in the bacterial cell wall (Fig. 8). The changes in the peak locations indicate the changes in the cytochrome proteins at $753 \mathrm{~cm}^{-1}$ and nucleic acids at $780-818 \mathrm{~cm}^{-1}$ (Table S1).

Figure 8a shows the 2D spectra between 700 and 800 $\mathrm{cm}^{-1}$, a region that covers the bands identified with cytochrome proteins, and a characteristic feature of bacterial decay. The 2D correlation plot of a clear zone of oregano oil treated bacteria shows intense positive autopeak at $737 \mathrm{~cm}^{-1}$ with negative cross-peaks across diagonal at $\left(753,737 \mathrm{~cm}^{-1}\right)$ and $\left(737,753 \mathrm{~cm}^{-1}\right)$. These peak shifts can be seen in the one-dimensional spectra with an increase in the concentration of oregano oil, there is a decrease in cytochrome proteins due to cell lysis. For an asynchronous map, there are two different cross-peaks with different signs: positive at $(737,746)$ and negative at $(750,753)$. These different signs show that changes in these peaks occur at opposite directions coinciding with each other. This indicates that 737 and $746 \mathrm{~cm}^{-1}$ bands are associated with non-viable bacteria while 750 and $753 \mathrm{~cm}^{-1}$ bands are associated with the bacterial state prior to the treatment with the biocide. Clear zone of oregano oil treated bacteria shows minimal 

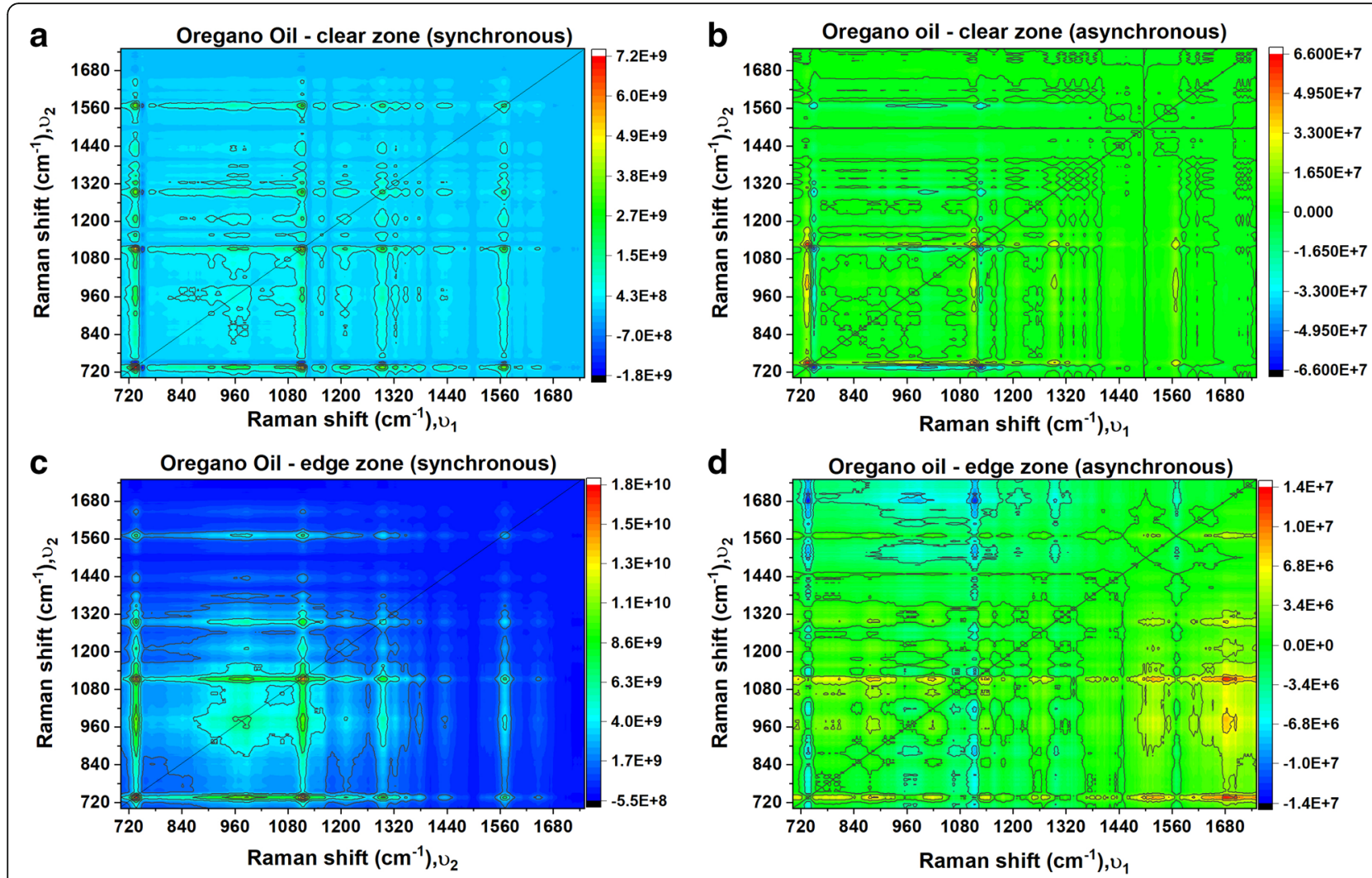

Fig. 7 Synchronous $(\mathbf{a}, \mathbf{c})$ and asynchronous $(\mathbf{b}, \mathbf{d})$ correlation spectra of clear and outer edge zone of bacterial cells exposed to oregano oil ranging concentrations from 0 to $30 \%$. (Intensity colour scale on the left)

trace of cytochrome signature with an increase in concentration, making it a preferential choice to use compared to TCMTB. An outer edge zone of oregano oil treated bacteria looks similar to TCMTB clear zone with autopeaks at $737,1125,1381$, and $1581 \mathrm{~cm}^{-1}$. Several cross-peaks were observed in the synchronous contour map with a positive peak at $\left(737 \mathrm{~cm}^{-1}, 1125 \mathrm{~cm}^{-1}\right)$ and negative peak at $\left(1381 \mathrm{~cm}^{-1}, 1125 \mathrm{~cm}^{-1}\right)$. Asynchronous map has band narrowing across the diagonal at 737, and $1081 \mathrm{~cm}^{-1}$ with significant in 1440 and $1648 \mathrm{~cm}^{-1}$ band was also altered in its biochemical components with decreasing cytochrome protein content, with variation in $\mathrm{CH}_{2}$ deformation of proteins and amide I protein bands which is not found in other biocides. The clear and outer edge zone has collaborative effort in fighting against bacteria making clear zone free from bacteria and outer edge zone also affected with biocide to expel. This demonstrates that oregano oil not only fights against the bacteria but also resists the other bacteria in its reach.

The mode of action of synthetic and natural biocides has been extensively studied in this paper. It has been reported that biocides target bacteria cell walls and create deformations in the outer membrane. Such exposure to biocides was followed by changes in ultrastructure related to a decrease in biocidal susceptibility, usually at a low concentration [36]. The benzothiazole ring of TCMTB binds to different biological targets in bacterial cells and inhibits the bacteria. Different biocides have different mechanisms for action against bacteria. A. hydrophila is Gram-negative bacteria, and studies suggested that Gram-negative bacteria appear to be more resistant than Gram-positive bacteria in response to essential oils [41], but our results with oregano oil doesn't support this. It was found that Gram negative bacteria, A. hydrophila, is sensitive to oregano oil in clear and edge zone of inhibition. The possibility that the cell wall and membrane were primary targets of oregano oil with disturbance of membrane-embedded proteins and disruption of lipids has been previously demonstrated [42]. Moreover, oregano oil may cause cell wall and membrane damage, and the formation of cytoplasmic vacuoles, eventually inducing cell necrosis, although more investigations are required to conclude the mechanism in detail. In summary, the action of synthetic biocides has higher toxicity and higher environmental impact to be used even at lower concentration levels.

\subsection{Antimicrobial effect of leather treated with biocides}

To demonstrate and assess research work effectiveness in the real-world setting, we have used TCMTB and 


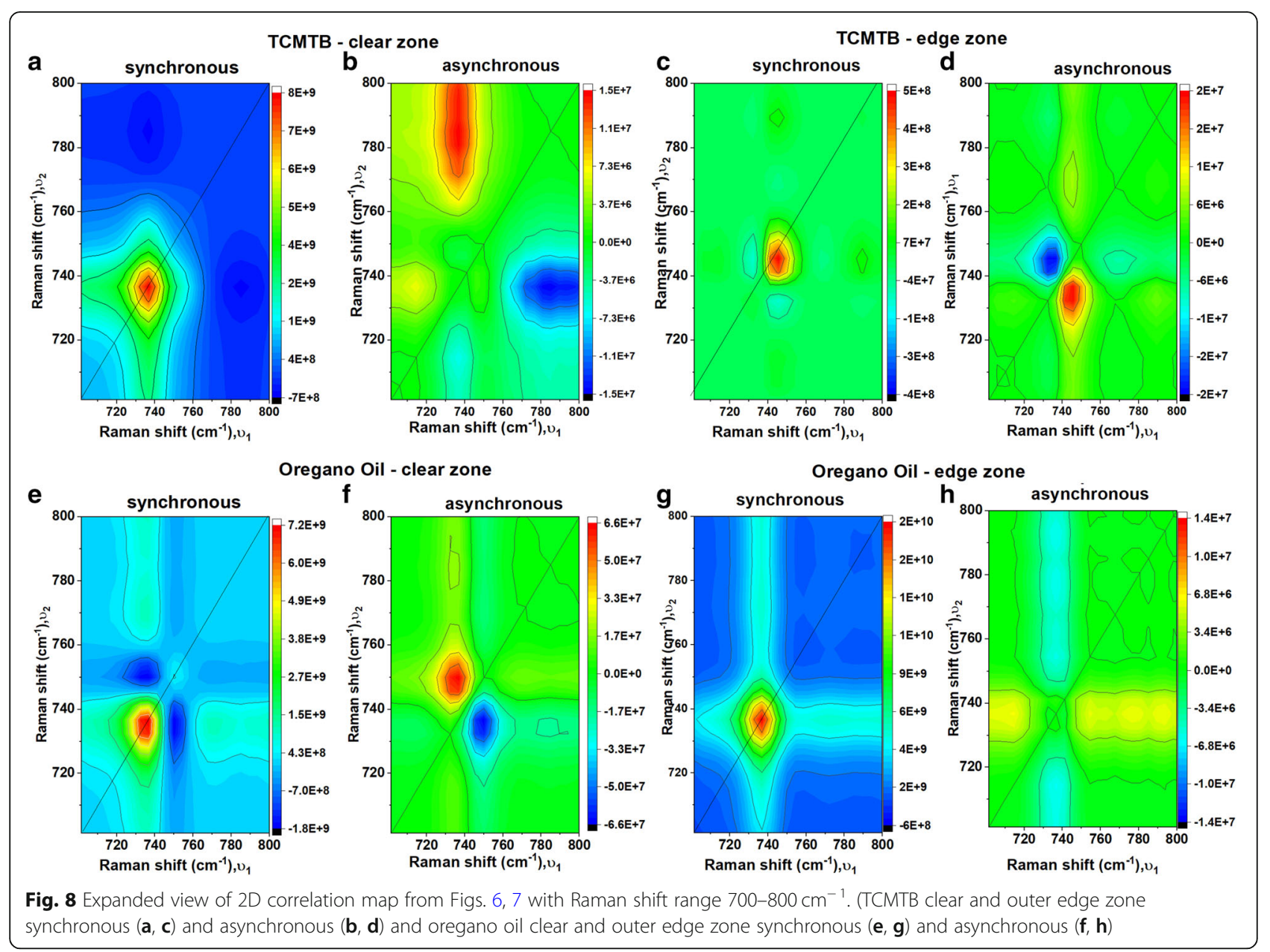

oregano oil biocides in leather processing, starting from fresh raw skin to the final finished leather. We believe this is the first study where synthetic and essential oil biocides were compared and studied in detail using Raman spectroscopy and chemometrics. This will also help in improving the leather process with a view of ecological aspects. Similar to disk diffusion assay method, we have replaced disk inoculated with TCMTB and oregano oil with $12 \mathrm{~mm}$ diameter leather disks in this experiment. The diameter of inhibition zone was measured, and Raman analysis was carried out on clear and outer edge zones of bacterium A. hydrophila. Figure 9a shows the control sample without any biocide has no inhibition zone, ТСMTB (1\% concentration used in standard leather processing) has inhibition zone of 18 $\mathrm{mm}$ diameter, $1 \%$ oregano oil of $18 \mathrm{~mm}$ and $2 \%$ oregano oil of $30 \mathrm{~mm}$. Raman spectral analysis of clear and outer edge zone of leather samples shows different spectral bacterial signature as compared to biocide inoculated disks. Leather has a different mechanism of interaction with bacterial cells, which modify its actual single cell signature. Figure 9b shows the oregano oil intensity of marker cytochrome protein bands at $754 \mathrm{~cm}^{-1}$ is absent and could not be distinguished from noise. TCMTB is known to cause mitochondrial damage resulting in apoptosis and morphological damage. The significant cytochrome protein marker band at $753 \mathrm{~cm}^{-1}$ observed in TCMTB spectra suggests the $753 \mathrm{~cm}^{-1}$ band is a marker for mitochondrial damage [43]. The low wavenumber region, $600-800 \mathrm{~cm}^{-1}$ contributes more to the noise for oregano oil Raman spectra. The detailed assignments are tabulated in Table S1. PCA analysis also provides better visibility separating the clear and outer edge zone indicating the variability in two sets. In this leather application work, the low biocide concentration served not only to kill the bacteria but also to stimulate the expression of resistance. Raman spectroscopy is a promising technique for detecting molecular changes induced by different classes of biocides in bacteria, discrimination of clear and outer edge zone of bacteria towards biocides, and thus allowing the comprehensive understanding of the mechanisms of antimicrobial resistance.

\section{Conclusions}

Our results show that we have developed a rapid, simple, and reliable Raman method that can reveal the biocide 
a

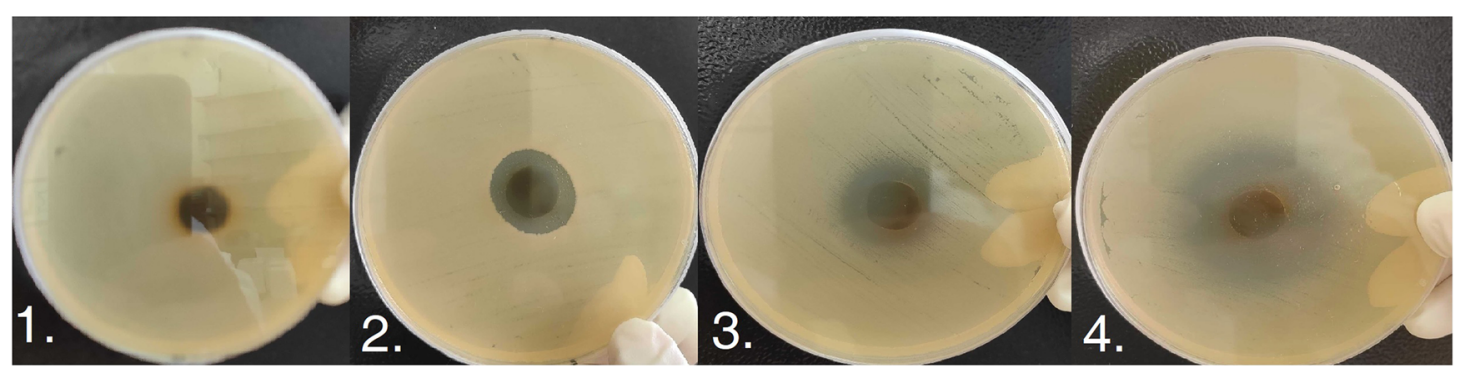

b
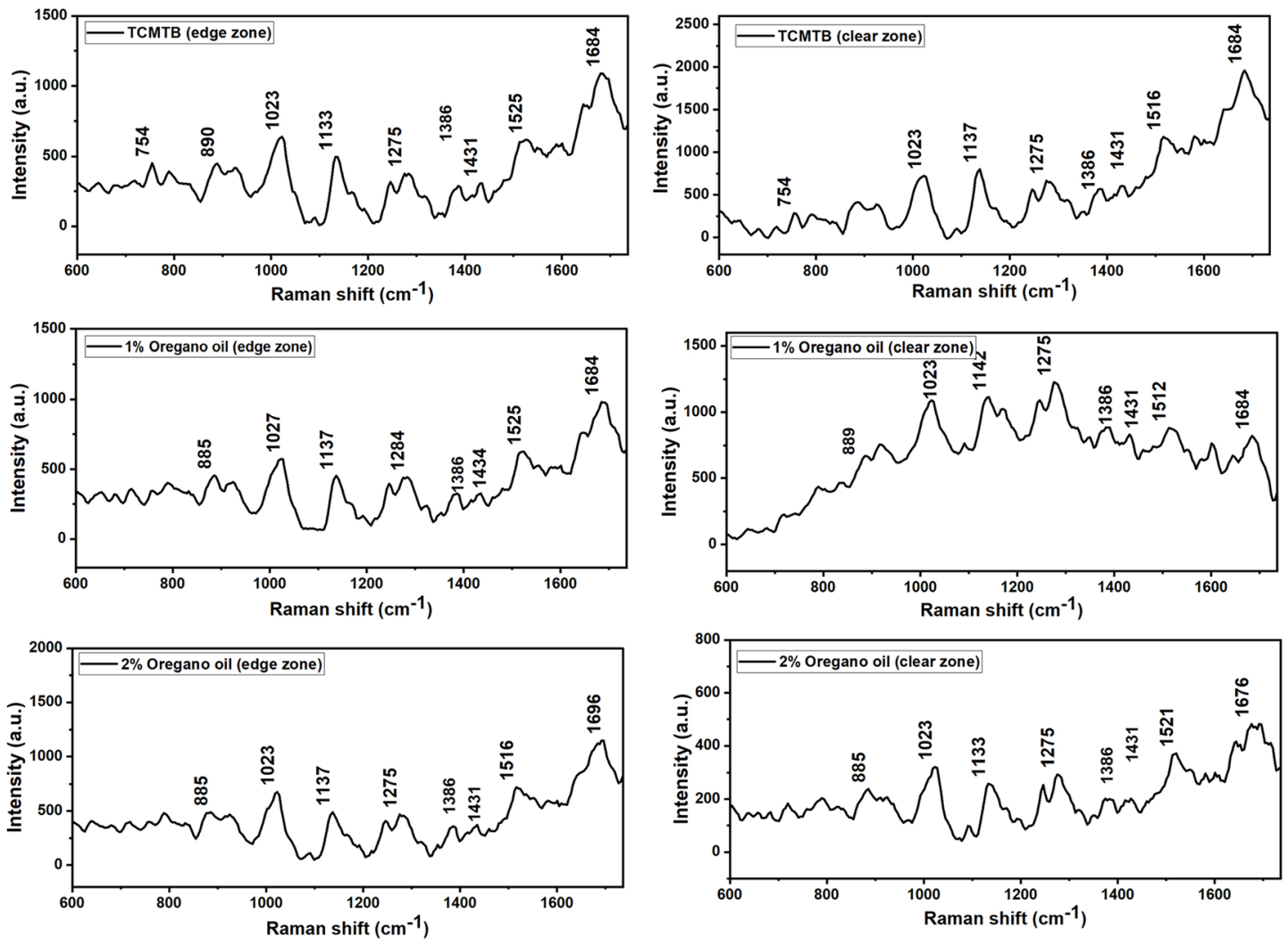

C

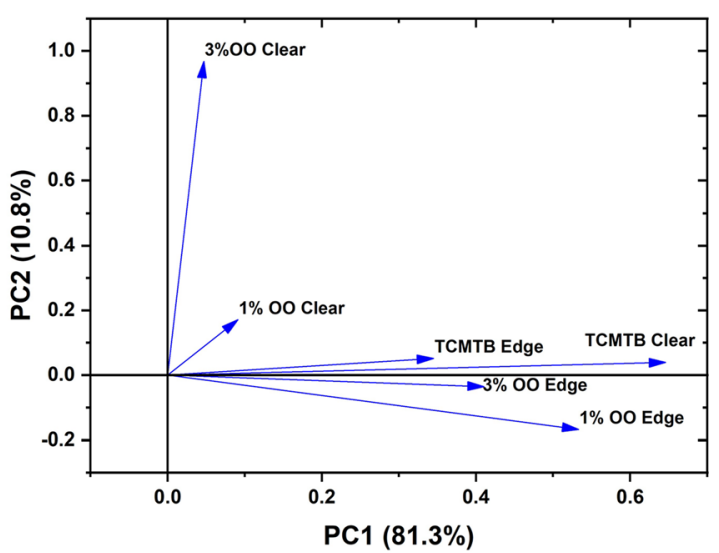

Fig. 9 a Leather samples treated (1) without any biocide, (2) with TCMTB, (3) $1 \%$ oregano oil and (4) $2 \%$ oregano oil during the processing $\mathbf{b}$ average Raman spectra from clear and outer edge zone of $A$. hydrophila grown in the presence of leather specimen inoculated with TCMTB, $1 \%$ oregano oil and 2\% oregano oil; c PCA score plot of the mentioned strains 
induced cellular changes in A. hydrophila bacterium cells. Significant spectral differences were clearly noticed in the Raman spectra after biocide treatment. Further peak assignment analysis provided more details on the biochemical profile changes in the bacterial cell wall and cell integrity. TCMTB shows better susceptibility comparative to dichlorophen in the class of synthetic biocides, whereas oregano oil delivers excellent results in terms of efficacy compared to eucalyptus oil. TCMTB induced significant variations in the biochemical profile of bacteria samples from clear and outer edge zone of inhibition, discriminating them into two groups using Principal Component Analysis (PCA). Clear zone bacteria have different sensitivity than edge zone bacteria because of their different modes of action. In contrast, oregano oil shows bactericidal properties by altering the bacteria significantly in clear and edge zone of inhibition at high concentrations, making it the best choice for $A$. hydrophila bacterium and can be useful on different microbes. Hence, $2 \%$ oregano oil was found to be one of the best ones in terms of safety and efficacy. Twodimensional correlation analysis was carried out to support the variations, and contour maps revealed the spectral features that are not visible in typical onedimensional Raman spectra.

We have demonstrated that introducing oregano oil into processing stages can protect leather quality. The results are entirely consistent with the traditional disk diffusion method and other analysis methods. In the future, we wish to extend the study to screen more biocides and microorganisms.

\section{Abbreviations \\ TCMTB: 2-(thiocyanomethylthio) benzothiazole; PCA: Principal component analysis; PBS: Phosphate Buffer Solution; DMSO: Dimethyl Sulfoxide; LB: Luria Broth; 2D-COS: Two-dimensional Correlation Spectroscopy; \\ DCP: Dichlorophen; A.hydrophila: Aeromonas hydrophila; PCMC: 4-chloro-3- methylphenol; OPP: 2-phenylphenol; PCP: Pentachlorophenol; RSL: Restricted Substances Lists; REACH: Registration, Evaluation, Authorisation, and Restriction of Chemicals}

\section{Supplementary Information}

The online version contains supplementary material available at https://doi. org/10.1186/s42825-021-00062-3.

Additional file 1: Table S1. Spectral peak assignments for the Raman bands of biocide affected bacteria samples observed at $532 \mathrm{~nm}$ excitation [20-23, 27, 35]. Figure S1. Main stages of leather processing (biocide application). Figure S2. a) Raman spectra of raw control data without baselining; b) Raman spectra of control data after baseline correction.

\section{Acknowledgements}

This work was supported by NZ Leather and Shoe Research Association $\left(\right.$ LASRA $\left.^{\oplus}\right)$, Palmerston North, New Zealand through the Ministry of Business, Innovation and Employment (MBIE) grant number LSRX1801.

\section{Authors' contributions}

M.M. conceptualized and designed the outline, conducted Raman experiments, data analysis and writing the manuscript; Yang Liu cultured bacteria and performed microbiology experiments; reviewed the manuscript; Mark Waterland provided the access to Raman lab, reviewed and edited the manuscript; and Geoff Holmes provided resources and funding to carry out the project. The author(s) read and approved the final manuscript.

Funding

The research is funded by the Ministry of Business, Innovation and Employment (MBIE) grant number LSRX1801.

\section{Availability of data and materials}

The datasets generated and analysed during the current study are available from the corresponding author on reasonable request.

\section{Declaration}

\section{Competing interests}

The authors declare that they have no competing interest.

\section{Author details}

${ }^{1}$ NZ Leather and Shoe Research Association (LASRA ${ }^{\oplus}$ ), Palmerston North, New Zealand. ${ }^{2}$ School of Fundamental Sciences, Massey University, Palmerston North, New Zealand.

Received: 21 March 2021 Accepted: 30 May 2021

Published online: 15 August 2021

\section{References}

1. Weckmann A, Tegtmeyer D, Kleban M. Leather biocides: a review of technical and regulatory requirements. IULTCS Congress Proc. 2017;34: 49-54.

2. Black M, Canova M, Rydin S, Scalet BM, Roudier S, Sancho LD. Best available techniques (BAT) reference document for the tanning of hides and skins. Eur Comm Database. 2013;46:2013.

3. Bielak E, Marcinkowska E, Syguła-Cholewińska J. Investigation of finishing of leather for inside parts of the shoes with a natural biocide. Sci Rep. 2020; 10(1):1-10.

4. CEC. Regulation (EC) no. 1907/2006 of the European Parliament and of the Council of 18 December 2006 concerning the Registration, Evaluation, Authorisation and Restriction of Chemicals (REACH). Brussels: EU CEC; 2006.

5. Proudfoot AT. Pentachlorophenol poisoning. Toxicol Rev. 2003;22(1):3-11. https://doi.org/10.2165/00139709-200322010-00002.

6. Harborne JB. Biochemistry of phenolic compounds; 1964.

7. Bielac E, Marcinkowska E, Sygula-Cholewinska J. The durability of antimicrobial effect of leathers finished with oregano oil. J Am Leather Chem Assoc. 2017;112(11):377-86.

8. Kopp W, Dos Santos C, Dos Santos JHZ, Gutterres M. Clove essential oilfree andE ncapsulatedf or antimicrobial leather. J Soc Leather Technol Chem. 2020;104(1):8-13.

9. Lu M, Dai T, Murray CK, Wu MX. Bactericidal property of oregano oil against multidrug-resistant clinical isolates. Front Microbiol. 2018;9:2329. https://doi. org/10.3389/fmicb.2018.02329.

10. Bayramoglu E. Unique biocide for the leather industry. J Am Leather Chem Assoc. 2007;102(11):347-52.

11. Bayramoglu EE, Gulumser G, Karaboz I. Ecological and innovative fungicide for the leather industry: essential oil of Origanum minutiflorum. J Am Leather Chem Assoc. 2006;101(3):96-104.

12. Sirvaityte J, Siugzdaite J, Valeika V, Dambrauskiene E. Application of essential oils of thyme as a natural preservative in leather tanning. Proc Est Acad Sci. 2012;61(3):220. https://doi.org/10.3176/proc.2012.3.12.

13. Verma T, Annappa H, Singh S, Umapathy S, Nandi D. Profiling antibiotic resistance in Escherichia coli strains displaying differential antibiotic susceptibilities using Raman spectroscopy. J Biophotonics. 2021;14(1): e202000231. https://doi.org/10.1002/jbio.202000231.

14. Hudzicki J. Kirby-Bauer disk diffusion susceptibility test protocol; 2009.

15. Athamneh A, Alajlouni R, Wallace R, Seleem M, Senger R. Phenotypic profiling of antibiotic response signatures in Escherichia coli using Raman spectroscopy. Antimicrob Agents Chemother. 2014;58(3):1302-14. https:// doi.org/10.1128/AAC.02098-13.

16. Stratev D, Odeyemi OA. Antimicrobial resistance of Aeromonas hydrophila isolated from different food sources: a mini-review. J Infect Public Health. 2016;9(5):535-44. https://doi.org/10.1016/j.jiph.2015.10.006. 
17. Seshadri R, Joseph SW, Chopra AK, Sha J, Shaw J, Graf J, et al. Genome sequence of Aeromonas hydrophila ATCC 7966T: jack of all trades. J Bacteriol. 2006;188(23):8272-82. https://doi.org/10.1128/JB. 00621-06.

18. Mehta M, Liu Y, Waterland M, Holmes G. Characterization of the degradation of sheepskin by monitoring Cytochrome $\mathrm{c}$ of bacteria by Raman spectroscopy. Anal Lett. 2021;54(6):1005-22. https://doi.org/10.1080/ 00032719.2020 .1792476$.

19. Szöke-Nagy T, Porav AS, Coman C, Cozar BI, Dina NE, Tripon C. Characterization of the action of antibiotics and essential oils against bacteria by surface-enhanced Raman spectroscopy and scanning electron microscopy. Anal Lett. 2019;52(1):190-200. https://doi.org/10.1080/0003271 9.2018.1430150

20. Harz M, Rösch P, Popp J. Vibrational spectroscopy-a powerful tool for the rapid identification of microbial cells at the single-cell level. Cytom Part A J Int Soc Anal Cytol. 2009;75(2):104-13.

21. Buitinck L, Louppe G, Blondel M, Pedregosa F, Mueller A, Grisel O, et al. API design for machine learning software: experiences from the scikit-learn project. arXiv preprint arXiv:13090238. 2013.

22. Lasch P, Noda I. Two-dimensional correlation spectroscopy (2D-COS) for analysis of spatially resolved vibrational spectra. Appl Spectrosc. 2019;73(4): 359-79. https://doi.org/10.1177/0003702818819880.

23. Pätzold R, Keuntje M, Theophile K, Müller J, Mielcarek E, Ngezahayo A, et al. In situ mapping of nitrifiers and anammox bacteria in microbial aggregates by means of confocal resonance Raman microscopy. Journal of Microbiological Methods. 2008;72(3):241-8.

24. Pätzold R, Keuntje M, Theophile K, Müller J, Mielcarek E, Ngezahayo A, et al. In situ mapping of nitrifiers and anammox bacteria in microbial aggregates by means of confocal resonance Raman microscopy. J Microbiol Methods. 2008;72(3):241-8. https://doi.org/10.1016/j.mimet.2007.12.003.

25. Notingher I, Hench LL. Raman microspectroscopy: a noninvasive tool for studies of individual living cells in vitro. Expert Rev Med Devices. 2006;3(2): 215-34. https://doi.org/10.1586/17434440.3.2.215.

26. De Gelder J, De Gussem K, Vandenabeele P, Moens L. Reference database of Raman spectra of biological molecules. J Raman Spectrosc Int J Orig Work All Asp Raman Spectrosc Incl High Order Process Also Brillouin Rayleigh Scatt. 2007;38(9):1133-47.

27. Ren Z, Meyer T, McRee DE. Atomic structure of a cytochrome $c^{\prime}$ with an unusual ligand-controlled dimer dissociation at 1. $8 \AA$ resolution. J Mol Biol. 1993;234(2):433-45. https://doi.org/10.1006/jmbi.1993.1597.

28. Teng L, Wang X, Wang X, Gou H, Ren L, Wang T, et al. Label-free, rapid and quantitative phenotyping of stress response in E. coli via ramanome. Sci Rep. 2016;6(1):1-10.

29. Talari ACS, Movasaghi Z, Rehman S, Rehman IU. Raman spectroscopy of biological tissues. Appl Spectrosc Rev. 2015;50(1):46-111. https://doi.org/10.1 080/05704928.2014.923902.

30. Mehta M, Naffa R, Maidment C, Holmes G, Waterland M. Raman and ATRFTIR spectroscopy towards classification of wet blue bovine leather using ratiometric and chemometric analysis. J Leather Sci Eng. 2020;2(1):3. https:// doi.org/10.1186/s42825-019-0017-5.

31. Lopez-Romero JC, González-Ríos H, Borges A, Simões M. Antibacterial effects and mode of action of selected essential oils components against Escherichia coli and Staphylococcus aureus. Evid Based Complement Alternat Med. 2015;2015:1-9. https://doi.org/10.1155/2015/795435.

32. Hu S, Morris IK, Singh JP, Smith KM, Spiro TG. Complete assignment of cytochrome c resonance Raman spectra via enzymic reconstitution with isotopically labeled hemes. J Am Chem Soc. 1993;115(26):12446-58. https:// doi.org/10.1021/ja00079a028

33. Hamada K, Fujita K, Smith NI, Kobayashi M, Inouye Y, Kawata S. Raman microscopy for dynamic molecular imaging of living cells. J Biomed Opt 2008;13(4):044027. https://doi.org/10.1117/1.2952192.

34. Wood BR, Langford SJ, Cooke BM, Lim J, Glenister FK, Duriska M, et al. Resonance Raman spectroscopy reveals new insight into the electronic structure of $\beta$-hematin and malaria pigment. J Am Chem Soc. 2004;126(30): 9233-9. https://doi.org/10.1021/ja038691x

35. Abramczyk H, Brozek-Pluska B, Kopec M, Surmacki J, Błaszczyk M, Radek M. Redox imbalance and biochemical changes in Cancer by probing redoxsensitive mitochondrial cytochromes in label-free visible resonance Raman imaging. Cancers. 2021;13(5):960. https://doi.org/10.3390/cancers13050960.

36. Henly E, Dowling J, Maingay J, Lacey M, Smith T, Forbes S. Biocide exposure induces changes in susceptibility, pathogenicity, and biofilm formation in uropathogenic Escherichia coli. Antimicrobial agents and chemotherapy. 2019;63(3).

37. Jung GB, Lee YJ, Lee G, Park HK. A simple and rapid detection of tissue adhesive-induced biochemical changes in cells and DNA using Raman spectroscopy. Biomed Opt Express. 2013;4(11):2673-82. https://doi.org/10.13 64/BOE.4.002673.

38. Fox SA. Raman micro-spectroscopy and multivariate analysis for the skin; 2013.

39. Dybas J, Grosicki M, Baranska M, Marzec KM. Raman imaging of heme metabolism in situ in macrophages and Kupffer cells. Analyst. 2018;143(14): 3489-98. https://doi.org/10.1039/C8AN00282G.

40. López-Díez EC, Winder CL, Ashton L, Currie F, Goodacre R. Monitoring the mode of action of antibiotics using Raman spectroscopy: investigating subinhibitory effects of amikacin on Pseudomonas aeruginosa. Anal Chem. 2005;77(9):2901-6. https://doi.org/10.1021/ac048147m.

41. Gao C, Tian C, Lu Y, Xu J, Luo J, Guo X. Essential oil composition and antimicrobial activity of Sphallerocarpus gracilis seeds against selected foodrelated bacteria. Food Control. 2011;22(3-4):517-22. https://doi.org/10.1016/j. foodcont.2010.09.038.

42. Tapia-Rodriguez MR, Hernandez-Mendoza A, Gonzalez-Aguilar GA, MartinezTellez MA, Martins CM, Ayala-Zavala JF. Carvacrol as potential quorum sensing inhibitor of Pseudomonas aeruginosa and biofilm production on stainless steel surfaces. Food Control. 2017;75:255-61. https://doi.org/10.101 6/j.foodcont.2016.12.014

43. Hu S, Morris IK, Singh JP, Smith KM, Spiro TG. Complete assignment of cytochrome c resonance Raman spectra via enzymatic reconstitution with isotopically labeled hemes. J Am Chem Soc. 1993;115(26):12446-58. https:// doi.org/10.1021/ja00079a028.

\section{Publisher's Note}

Springer Nature remains neutral with regard to jurisdictional claims in published maps and institutional affiliations.

\section{Submit your manuscript to a SpringerOpen ${ }^{\circ}$ journal and benefit from:}

- Convenient online submission

- Rigorous peer review

- Open access: articles freely available online

- High visibility within the field

- Retaining the copyright to your article

Submit your next manuscript at $\boldsymbol{\nabla}$ springeropen.com 